\title{
Formación en servicio de profesores de ciencias naturales a través de la educación CTS:
} reflexiones para la educación pública

\author{
Rosangela Cristina Rocha Auriglietti \\ rcrrosangelarocha@gmail.com \\ https://orcid.org/0000-0002-5317-0041 \\ Universidade Federal do Paraná- UFPR \\ Curitiba - PR
}

\section{Leonir Lorenzetti}

leonirlorenzetti22@gmail.com

http://orcid.org/0000-0002-0208-2965

Universidade Federal do Paraná - UFPR

Curitiba - PR.

Recibido: 15/marzo/2021 Aceptado: 31/agosto/2021

\section{Resumen}

Este estudio tuvo como objetivo analizar cómo la formación en servicio, a partir de los supuestos de la Educación CTS, desarrollada con un grupo de profesores de Ciencias de la Naturaleza de secundaria de una escuela pública de la red estatal de Paraná, puede contribuir a reflexionar sobre la práctica pedagógica y favorecer la construcción de secuencias didácticas priorizando el trabajo interdisciplinario y la interrelación de Ciencia, Tecnología y Sociedad. El enfoque metodológico involucró la investigación cualitativa y la técnica de los grupos focales, buscando la inversión del estilo de educación continua conocido por el grupo, partiendo de la realidad vivida y no de los modelos teóricos aplicables. La constitución de los datos se realizó a través de entrevistas semiestructuradas, análisis de las discusiones generadas durante las reuniones del grupo de estudio y organización de una secuencia didáctica. Estos elementos fueron categorizados y discutidos utilizando la metodología de análisis de contenido. Se pudo entender que, a pesar de no conocer el Movimiento Ciencia-Tecnología-Sociedad, muchos docentes abordan los supuestos CTS en sus acciones educativas, priorizando en ocasiones la ciencia o la sociedad, factor que hay que superar. Las dificultades estructurales, metodológicas y sociales que enfrentan los docentes en la vida cotidiana de las escuelas públicas interfieren negativamente en sus acciones, inhibiendo el trabajo contextualizado e interdisciplinario, enfatizando los contenidos del programa prescriptivo.

Palavras-chave: Formación continuada. Enseñanza CTS. Ciencias de la Naturaleza.

\section{A formação em serviço de professores de ciências da natureza por meio da educação CTS: reflexões para a educação pública}

\section{Resumo}

Este estudo teve por objetivo analisar como uma formação em serviço, baseada nos pressupostos da Educação CTS, desenvolvida com um grupo de professores de Ciências da Natureza do Ensino Médio de uma escola pública da rede estadual do Paraná, pode contribuir para refletir sobre a prática pedagógica e favorecer a construção de sequências didáticas priorizando o trabalho interdisciplinar e a inter-relação Ciência, Tecnologia e Sociedade. A abordagem 
metodológica envolveu a pesquisa qualitativa e a técnica do grupo focal, visando a inversão de estilo de formação continuada conhecida pelo grupo, partindo da realidade vivida e não de modelos teóricos aplicáveis. A constituição de dados se deu por meio de entrevistas semiestruturadas, análise das discussões geradas durante as reuniões do grupo de estudos e organização de sequência didática. Esses elementos foram categorizados e discutidos pela metodologia de análise do conteúdo. Foi possível compreender que, apesar de não conhecerem o Movimento ciência-tecnologia-sociedade, muitos professores abordam em suas ações educativas pressupostos CTS, às vezes priorizando a ciência ou a sociedade, fator que precisa ser superado. As dificuldades estruturais, metodológicas e sociais que os professores enfrentam no cotidiano da escola pública interferem negativamente em suas ações, inibindo um trabalho contextualizado e interdisciplinar, dando ênfase no conteúdo programático prescritivo.

Palavras-chave: Formação continuada. Ensino CTS. Ciências da Natureza.

\title{
In-service training of teachers of natural sciences through STS education: reflections for public education
}

\begin{abstract}
This study aimed to analyze how in-service training, based on the assumptions of STS Education, developed with a group of High School Nature Science teachers from a public school in the state network of Paraná, can contribute to reflect on the pedagogical practice and favor the construction of didactic sequences prioritizing interdisciplinary work and the interrelation of Science, Technology and Society. The methodological approach involved qualitative research and the focus group technique, aiming at the inversion of the continuing education style known by the group, starting from the lived reality and not from applicable theoretical models. The constitution of data took place through semi-structured interviews, analysis of the discussions generated during the study group meetings and organization of a didactic sequence. These elements were categorized and discussed using the content analysis methodology. It was possible to understand that, despite not knowing the Science-technology-Society Movement, many teachers address STS assumptions in their educational actions, sometimes prioritizing science or society, a factor that needs to be overcome. The structural, methodological and social difficulties that teachers face in the daily life of public schools interfere negatively in their actions, inhibiting contextualized and interdisciplinary work, emphasizing the prescriptive program content.
\end{abstract}

Keywords: Continuing education. CTS Teaching. Natural Sciences.

\section{Introdução}

Nas escolas públicas estaduais do Estado do Paraná cabe as pedagogas acompanhar os professores das diferentes áreas do conhecimento na elaboração de seus planos de trabalho, elaborar e disseminar a proposta pedagógica da escola e seu Projeto Político Pedagógico. Como pedagoga, a primeira autora, tem participado em diferentes cursos de formação continuada 
promovido pela Secretaria Estadual de Educação, compartilhado com os docentes as angústias quanto às crescentes dificuldades de ensinar nos dias atuais.

Também percebe o anseio dos professores por desenvolver uma educação pública de qualidade, que promova a construção de saberes, o desejo de ter seu trabalho reconhecido, tanto pelos estudantes, quanto pela sociedade e poder público. Contudo, os professores se deparam com salas de aulas lotadas, desinteresse dos estudantes, falta de estrutura mínima para prática do trabalho, dentre outros fatores que, muitas vezes, desestimulam e colocam no professor o peso do fracasso escolar.

Em discussões com os professores acerca do desenvolvimento do processo de ensino e de aprendizagem, bem como dos cursos de formação de que participam, é comum a narrativa do quanto os cursos estão distantes da realidade, tanto do estudante, quanto das necessidades docentes.

Tratando-se das disciplinas da Ciência da Natureza, as dificuldades de ensinoaprendizagem são mais presentes, pois os currículos escolares, livros didáticos e cursos de formação ainda trazem uma visão empírico-positivista, mais centrada na transmissão de conhecimento do que na sua construção. Auxiliar o estudante a compreender o que é ciência, suas aplicações e implicações, como relaciona-se com a sociedade e a tecnologia é uma problemática a ser aprofundada.

Assim, neste artigo analisamos como uma formação em serviço, baseada nos pressupostos da Educação Ciência, Tecnologia e Sociedade (CTS), com um grupo de professores de Química, Física e Biologia do Ensino Médio de uma escola pública estadual, pode contribuir para refletir sobre a prática pedagógica e favorecer a construção de sequências didáticas que priorizem o trabalho interdisciplinar e a inter-relação Ciência, Tecnologia e Sociedade.

Esse artigo é resultado de dissertação de mestrado que discutiu as relações entre educação CTS e a formação de professores de Ciências da Natureza em uma escola pública estadual de Ensino Médio, argumentando e refletindo sobre a apropriação do conhecimento das ciências e suas bases para o exercício da cidadania, tendo a instituição escolar como instância socializadora.

\section{A Educação CTS na formação continuada de professores}


Segundo Chrispino (2017) é difícil referenciar o surgimento da ideia CTS, pois várias correntes de pensamento apresentam referência a este estudo. $\mathrm{O}$ autor demarcar como um possível ponto de início do movimento os estudos sociológicos de Robert Merton (1910-2003) que em suas pesquisas discorria sobre a função social da ciência e o poder da atividade científica nas transformações sociais. Chrispino (2017) explana que foram antecipações como as de Robert Merton que permitiram que a ciência e a tecnologia, assim como seus impactos na sociedade, passassem a ser motivos de estudos e ganhassem espaços em diferentes meios como o político, o social, midiático ou educacional.

O foco do movimento CTS consiste em desmistificar concepções de neutralidade, essencialismo, salvacionismo e autonomia da ciência e da tecnologia, como considerar os impactos sociais e ambientais que essas concepções implantaram. A Educação CTS, decorrente do movimento CTS, foi introduzida no Brasil nos finais dos anos 80 do século passado, começando a fazer parte dos currículos educacionais com vistas a um ensino que contribuísse para “a compreensão e uso da tecnologia e a consolidação da democracia” (Strieder, 2008, p. 26).

Para Strieder (2008), o que impulsionou esse novo pensar foi a crise econômica no país, a industrialização e o questionamento de modelos norte-americanos, que colocam o Brasil na posição de dependência econômica e cientifica de países mais industrializados.

A tentativa de transformar a ciência e a tecnologia em um objeto de estudo público e associá-las a estratégias de desenvolvimento social e econômico, tomam forma na América Latina por meio do Pensamento Latino-Americano de Ciência, Tecnologia e Sociedade (PLACTS), tendo como objetivo tornar CT significativa e funcional à população, não excluindo a importação de conhecimentos tecnocientífico, mas adequando políticas sociais que utilizem esses conhecimentos em prol de compromissos sociais amplos (Silva, 2016).

Pensar o Ensino de Ciências sob o viés CTS, na escola pública, é extrapolar a simples conceituação de conteúdo e passar a refletir sobre o conhecimento científico-tecnológico, seja na sua produção, seja no seu uso e implicações socioculturais, para que realmente contribua para a formação de cidadãos cientificamente alfabetizados. Essa perspectiva implica ir além da simples inclusão de temas sociais nos currículos, de superar tendências educacionais enraizadas que trazem para a prática dos profissionais da educação a reprodução e transmissão de conhecimentos em uma perspectiva tradicional de ensino. 
Santos e Mortimer (2000) chamam a atenção para a questão do desenvolvimento de valores que envolvam o interesse coletivo, destacando solidariedade, consciência do compromisso social, reciprocidades humanas, questionamento à ordem capitalista. A inserção dessas premissas nas discussões irá contribuir para a "formação do cidadão crítico e comprometido com a sociedade" (Santos e Mortimer, 2000, p. 114).

A formação cidadã, como pressuposto para o desenvolvimento do estudante, em seu sentido amplo, culmina na participação efetiva nos processos sociais, posicionando-se como sujeito histórico e consciente. A escola pública, mesmo considerando todos os problemas que enfrenta, ainda é o espaço institucional para a formação da cidadania, devendo ser incorporada e discutida em processos de formação de professores e implementada no contexto escolar.

O processo de formação continuada tem um longo percurso no contexto histórico do Brasil. Alferes e Mainardes (2011) demarcam seu nascimento ainda na década de 60 do século passado, galgado em momentos políticos distintos: ditadura militar, movimento de democratização da sociedade e movimento de globalização da cultura e da economia. Cada momento influenciou os processos de formação continuada de alguma forma, sempre tendo por objetivo atualizar o corpo docente das escolas públicas brasileiras, fundamentados por uma pedagogia de transmissão de conhecimento, compreendendo conhecimento apenas como conceitos científicos preestabelecidos.

A LDB 9394/96 abriu pressupostos para a discussão em torno da formação continuada e o contexto político-econômico e social, coadunando com muitos estudiosos da educação na defesa de uma formação que se concretizasse embasada por pressupostos progressivos, abordando reflexões acerca da prática em sala de aula, de metodologias de ensino que considerassem o conhecimento científico conceitual tanto quanto a realidade social, política e econômica e sua influência na vida de todos os cidadãos (Alferes e Mainardes, 2011).

Maués (2003) relata que todo esse debruçar-se sob a formação de professores impõe um novo perfil de profissional, um que exerce sua função seguindo os preceitos da sociedade do conhecimento, que compreende o professor como protagonista das reformas educacionais, como "peça-chave" para a efetivação das políticas educacionais em vigor.

Conforme apontamentos de Maués (2003), Alvarado-Prada, Alferes e Mainardes (2010), as políticas públicas iniciadas a partir da LDB 9394/96 levaram a um esvaziamento do processo reflexivo do professor da escola pública. Ou seja, almejou-se uma estrutura de formação que 
conseguisse sanar problemas de aprendizagem conceitual e social, mas na prática os professores tornaram-se executores de tarefas, sendo que as formações oferecidas lhes tiraram a autonomia de pensar sobre a própria prática.

No ano de 2015, o Conselho Nacional de Educação instituiu a Resolução nº 02/2015, definindo as Diretrizes Curriculares Nacionais para a formação inicial e continuada dos profissionais da Educação Básica a ser realizada em nível superior. Estipulou princípios, fundamentos, dinâmica formativa e procedimentos que deveriam ser observados a partir de então nos processos de formação.

Políticas de formação continuada precisam articular-se a outras políticas devido a multiplicidade de ações e intervenções que a formação de professores exige (Alferes e Mainardes, 2011). Freire (1996), Pimenta (1999), e Delizoicov (2002) atentam para a necessidade de os cursos de formação continuada caminharem no sentido de garantir aos educadores a autonomia, fundamentada em uma prática crítico reflexiva, vencendo o “distanciamento epistemológico" da prática (Freire, 1996, p.39), e envolvendo-se em todos os momentos da formação, considerando tanto os saberes já constituídos, quanto suas especificidades pedagógicas.

Desde 2004 a formação continuada de professores nas escolas públicas do Estado do Paraná passou por muitas mudanças, com as propostas de políticas públicas implantadas pelo governo deste período.

A Semana Pedagógica, principal meio de formação continuada oferecida pela SEED, acontece no primeiro e no segundo semestre de cada ano letivo, de acordo com o calendário escolar vigente. Conta com a participação de toda a comunidade escolar e envolvimento dos Núcleos Regionais de Educação.

Em relação à ciência, seja como processo de ensino, seja como tema relevante e emergente, não é incluído nos materiais de estudo, salvo algumas propostas de divulgação do uso de tecnologia assistida, como recurso pedagógico, o que indica uma visão instrumental da ciência e da tecnologia.

Binatto (2015) apresenta em sua pesquisa considerações relevantes com vistas a vencer a fragmentação de propostas que contemplam abordagem CTS. O autor destaca a necessidade de refletir sobre como formar, mas sem desconsiderar os pressupostos que embasam e 
possibilitam a realização de propostas para esse fim, ou seja, é preciso considerar as bases epistemológicas que fundamentam essa formação.

Ciente de que a escola pública não é o único espaço de desenvolvimento e difusão de conhecimento, concorda-se que ela se constitui em espaço precípuo do processo de construção de saberes e, por conseguinte, na promoção de cidadania consciente, autônoma e competente. São conceitos básicos de uma educação escolar o aprendizado das ciências em geral, como do entendimento de que esse aprendizado congrega reflexões e ações sobre a sociedade em que se está inserido e no exercício da cidadania (Binatto, 2015).

Em se tratando de interdisciplinaridade e contextualização, de acordo com as Diretrizes Curriculares Nacionais do Ensino Médio (DCNEM, 1998), ambas formam o eixo organizador curricular manifestada na LDB de 1996, suscitando preceitos de ensinar e aprender de forma integrada. Kato e Kawasaki $(2011$, p. 1) explanam que "a necessidade da contextualização do ensino surgiu em um momento da educação formal no qual os conteúdos escolares eram apresentados de forma fragmentada e isolada, apartados de seus contextos de produção científica, educacional e social".

Whartha, Silva e Bejarano (2013) atentam para o fato de se diferenciar cotidianização de contextualização. Segundo os autores existe na vida cotidiana elementos e comportamentos que podem ser campos de estudos por estarem embutidos na vida das pessoas e com isso definirem ações e comportamento que se vivencia diante de determinados fenômenos, mas que as ações cotidianas são executadas sem uma reflexão prévia, sem pensar sobre o agir de maneira crítica, levando os sujeitos a generalização, movidos por experiências empíricas.

A abordagem das relações entre ciência, tecnologia e sociedade descortina-se como possibilidade de um trabalho interdisciplinar e contextualizado por seu caráter questionador, tanto da sociedade, quanto dos caminhos percorridos pela ciência e da intencionalidade de formar cidadãos mais conscientes de seu papel social.

\section{Metodologia}

A abordagem metodológica utilizada foi a qualitativa de natureza interpretativa, adotando-se o método de análise de conteúdo, que complementa a abordagem qualitativa e 
suscita a oportunidade de explorar com afinco um determinado tema ou objeto de pesquisa (Mazza, Melo e Chiesa, 2009).

O estudo foi desenvolvido em uma escola pública estadual de Curitiba com o grupo de professores da área da Ciência da Natureza que atuam no Ensino Médio. Propôs-se analisar como uma formação em serviço, baseada nos pressupostos da Educação CTS, desenvolvida com um grupo de professores de Ciências da Natureza do Ensino Médio de uma escola pública da rede estadual do Paraná, pode contribuir para refletir sobre a prática pedagógica.

A constituição de dados ocorreu por meio de questionários com perguntas semiestruturadas, desenvolvimento de grupo de estudo e elaboração de uma sequência didática (SD). Para a constituição dos dados utilizou-se como técnicas a observação, gravações em áudio e transcrição na íntegra das falas dos participantes. Dos 10 professores que ministram os componentes Física, Química e Biologia, 7 concordaram em participar da pesquisa, sendo 3 professores de Biologia, 3 de Física e um de Química. Neste estudo os professores serão denominados de P1, P2, P3, P4, P5, P6, P7, mantendo o seu anonimato.

O estudo foi desenvolvido de março de 2019 a julho de 2019, conforme Quadro 1. O grupo de estudo teve carga horária de 40 horas, divididas em encontros presenciais e atividades a distância, envolvendo leituras prévias para discussões nos encontros presenciais. Os encontros ocorreram durante as horas de estudo e planejamento dos professores, denominados horaatividade, ocorrendo às quartas-feiras. Os professores têm 4 horas-aula semanais destinadas a esses momentos.

QUADRO 1: ESTRUTURA METODOLÓGICA DA PESQUISA

\begin{tabular}{|c|c|c|c|}
\hline Etapa & Desenvolvimento & Ações da pesquisa & Constituição de dados \\
\hline 1 & $\begin{array}{l}\text { Identificando } \\
\text { situações problemas } \\
\text { que dificultam o } \\
\text { processo de ensino e } \\
\text { de aprendizagem. } \\
\\
\text { Apresentação do } \\
\text { Movimento, } \\
\text { Educação e } \\
\text { Abordagem CTS. }\end{array}$ & $\begin{array}{l}\text { Convite para participar de uma } \\
\text { reflexão sobre as principais } \\
\text { dificuldades encontradas no } \\
\text { encaminhamento das práticas. } \\
\text { Ações educativas, considerando as } \\
\text { disciplinas de Biologia, Física e } \\
\text { Química. } \\
\text { Discussão sobre a possibilidade de } \\
\text { o grupo desenvolver um estudo, } \\
\text { tendo como base a teoria do } \\
\text { Movimento CTS e a partir do } \\
\text { estudo organizar sequências } \\
\text { didáticas de abordagem CTS. }\end{array}$ & $\begin{array}{l}\text { Discussão em grupo, gravação de } \\
\text { áudio. }\end{array}$ \\
\hline
\end{tabular}




\begin{tabular}{|l|l|l|l|}
\hline 2 & $\begin{array}{l}\text { Formulação e } \\
\text { desenvolvimento de } \\
\text { estratégias de ação }\end{array}$ & $\begin{array}{l}\text { Execução da proposta de } \\
\text { formação continuada sob a ótica } \\
\text { da Educação CTS. }\end{array}$ & $\begin{array}{l}\text { Entrevista semiestruturada. } \\
\text { Estudos de textos: Movimento, } \\
\text { Educação e Abordagem CTS. } \\
\text { Discussão e reflexão sobre as } \\
\text { leituras realizadas e a compreensão } \\
\text { dos pressupostos do Movimento } \\
\text { CTS. }\end{array}$ \\
\hline 3 & $\begin{array}{l}\text { Ampliação e } \\
\text { compreensão da nova } \\
\text { situação para } \\
\text { planejamento de } \\
\text { propostas de ensino. }\end{array}$ & $\begin{array}{l}\text { Apresentação das percepções dos } \\
\text { professores em relação ao } \\
\text { Movimento CTS. }\end{array}$ & $\begin{array}{l}\text { Registros realizados por meio de } \\
\text { gravações e respostas escritas sobre } \\
\text { as leituras realizadas. }\end{array}$ \\
\hline $\begin{array}{l}\text { Repensando as } \\
\text { situações-problema } \\
\text { indicadas no início da } \\
\text { proposta } \\
\text { considerando os } \\
\text { estudos realizados e a } \\
\text { possibilidade de uma } \\
\text { nova abordagem de } \\
\text { ensino. }\end{array}$ & $\begin{array}{l}\text { Organização de sequências } \\
\text { didáticas de abordagem CTS. }\end{array}$ & $\begin{array}{l}\text { nas } \\
\text { Comtrevistas, } \\
\text { base } \\
\text { grupo de estudo, nas gravações e } \\
\text { discussões realizadas. } \\
\text { Compilação dos materiais } \\
\text { produzidos pelo grupo durante a } \\
\text { formação continuada. }\end{array}$ \\
\hline
\end{tabular}

Fonte: Dados da Pesquisa

A finalização dos estudos desenvolveu-se por meio da organização de uma Sequência Didática, organização essa que foi discutida no grupo de estudos, tendo como referência para sua produção as pesquisas formuladas por Centa (2015) e Siemsen (2019). Para a organização da SD, considerou-se a abordagem metodológica dos 3 Momentos Pedagógicos (3MP) (Delizoicov, Angotti e Pernambuco, (2001) e as propostas de Zabala (1998).

Definiu-se como estratégia de análise a Análise de Conteúdo, que se caracteriza como um conjunto de técnicas de comunicações, realizada por meio de procedimentos sistemáticos e objetivos que descrevem conteúdos de mensagens (Bardin, 1977).

As definições erigidas na pré-análise, por meio da exploração dos materiais de pesquisa culminam na delimitação das unidades de registro e na sistematização das categorias de análise. Esta pesquisa constituiu-se, assim, por meio de análises de categorias a priori: Dimensões Epistemológicas e Dimensões Pedagógicas, e categorias a posteriori originando as categorias temáticas descritas na apresentação do corpus da pesquisa. A partir do corpus do trabalho, seguindo critérios progressivos e processuais, organizamos as análises na seguinte ordem: entrevistas, grupo de estudo e discussão, organização da sequência didática. Os movimentos de convergência entre categorias produziram o corpus a compor uma ou mais subcategorias a posteriori. 
As análises deram origem às categorias a) dimensão epistemológica englobando as subcategorias: i) concepção de ciência, tecnologia e sociedade; ii) conhecimento sobre CTS; iii) interdisciplinaridade e contextualização; b) dimensão pedagógica com as subcategorias: i) abordagem CTS para o processo ensino-aprendizagem; ii) produção da Sequência Didática.

\section{Análise e discussão dos dados}

Serão apresentadas a seguir as especificações sobre cada categoria, lembrando que, apesar da divisão entre dimensão epistemológica e dimensão pedagógica, em muitos momentos elas convergem, uma vez que não há como separar unilateralmente conhecimento científico do conhecimento prático, pois ambos estão imbricados na práxis pedagógica.

\section{Dimensão Epistemológica}

Considera-se como Dimensão Epistemológica os estudos e reflexões realizados a partir de aspectos históricos e constitutivos da natureza da ciência, da tecnologia e da sociedade, bem como a exploração, sob caráter mais amplo, de conhecimentos científicos que não se fechem em perspectivas positivistas, legitimando a ciência como conhecimento puro, mas que tenha a consciência de uma ciência de constituição social, cultural e tecnológica. Esses pressupostos são encontrados na concepção CTS, como aponta Angotti e Auth (2001).

Da categoria Dimensão Epistemológica emergiram as subcategorias: i) Concepção de ciência, tecnologia e sociedade; ii) Conhecimento sobre CTS; iii) Interdisciplinaridade e Contextualização.

A subcategoria "Concepção de ciência, tecnologia e sociedade" está vinculada ao conhecimento dos professores sobre essas temáticas, apoiadas por reflexões sobre conhecimento de CT e suas relações com a sociedade. Esta subcategoria emergiu das entrevistas e dos estudos realizados com o grupo.

Sobre o conhecimento dos professores em relação à ciência, os mesmos apresentam uma visão demasiada tecnicista e especializada, cuja existência se define em construir, desenvolver e melhorar as condições humanas, localizada acima do senso comum. Suas perspectivas aproximam-se do parâmetro discutido por Strieder (2012) de racionalidade científica, podendo 
ser encontrada em discursos sobre ciência, tecnologia e sociedade, representando uma maneira de delinear a ciência como também as relações CTS.

De acordo com o P4:

Não podemos dizer que só tem coisas boas, é claro é um conhecimento fundamental para o desenvolvimento humano, necessário também, mas já vivemos muitos problemas que foram causados pela ciência. A construção da bomba, por exemplo, é algo desenvolvido por cientistas, no entanto trouxe mais coisas ruins do que boas para a humanidade (P4, Entrevista).

Segundo Strieder (2012) discussões sobre a racionalidade científica e seu papel na ciência e na sociedade aparecem em discursos de vertentes empírico indutivista ou positivista, sobre tecnologia, ou inserem-se em valores pessoais e sociais, às vezes centrados na sociedade. Para a autora, atentar-se sobre racionalidade científica é mais do que olhar para ciência, é uma maneira de olhar para as relações CTS.

Durante a realização das entrevistas percebeu-se uma discrepância no pensar dos professores, sinalizando para dificuldade de compreender o papel da tecnologia tanto para a ciência como para sociedade. Percebeu-se em diferentes momentos da entrevista a dificuldade de comunicação, de entendimento da complexidade entre ciência, tecnologia e sociedade, indicando uma neutralidade que se relaciona à complexidade do tema e a carência de discuti-lo num processo de formação a fim de tornar claro e assim abordá-lo em sala de aula de maneira que se possa possibilitar aos estudantes também pensar e refletir sobre o assunto. A visão da tecnologia como técnica, produto da ciência ou método é discutida por Strieder (2012, p.103). Segundo a autora essa percepção se deve muitas vezes ao fato de autores falarem de tecnologia por esse viés funcional, pela "ideologização da técnica" que lhe atribui a capacidade de melhorar a vida do homem.

Visando explorar a reflexão do professor sobre essa influência, foi perguntado como ele vê a participação da sociedade na produção da ciência e da tecnologia, ao que ele respondeu:

Todos os dias recebemos informações sobre descobertas científicas e criação de ferramentas que contribuem para o desenvolvimento social e qualidade de vida das pessoas, para melhoria no ambiente, erradicação de doenças e execução de tarefas insalubre ao homem. Vemos que para os estudantes essas descobertas são feitas por pessoas especiais, superdotadas, que estão acima da população comum. Infelizmente a escola, da maneira que trabalha com a ciência reforça esta visão. É como se nossos alunos não sentissem capacidade de inovar, de criar, de pensar e refletir sobre o conhecimento, não se veem como parte deste processo (P1, Entrevista). 
Analisando o pensamento do professor e considerando a proposta de educação CTS, considera-se que a sociedade como um todo deveria ter condições científicas e sociais de intervir em questões relacionadas à ciência. Auler e Delizoicov (2001), ao apresentarem a classificação da visão ampliada em CTS como meio de ultrapassar os mitos da ciência, discutem que "a superação de uma percepção ingênua e mágica da realidade exige, cada vez mais, uma compreensão dos sutis e delicados processos de interação entre CTS” (Auler e Delizoicov, 2001, p. 129). De acordo com os autores, essa compreensão perpassa por considerar as temáticas locais como potenciais de reflexão e de construção de conhecimento, colocando em prática a educação dialógica e problematizadora, inserindo-a em questões que interferem diretamente na realidade vivida, conceito defendido pelo PLACTS.

As expressões dos professores demonstram a construção de uma visão realista sobre a ciência e fatores que interferem em sua produção como aplicação. Fatores esses que vão interferir diretamente no modo de ver e viver a produção científica. Coadunando com o pensamento desses participantes, Acevedo-Diaz (2006) declara a importância de compreender a prática científico-tecnológica, considerando, além da parte técnica, os aspectos organizacionais, políticos, administrativos e socioideológicos, abarcando objetivos e finalidades do uso da ciência e da tecnologia. Haja vista que uma educação científica construtiva precisa esclarecer que o conhecimento não independe de crenças ideológicas, que ciência é uma instituição social.

A subcategoria “Conhecimentos sobre CTS” agrupou as discussões realizadas no âmbito de identificar a compreensão do grupo sobre Educação CTS, seus pressupostos e abordagens. Quando indagados sobre a perspectiva CTS, a maioria dos participantes disseram não conhecer. Apenas o P3 relatou ter tido contato, ainda que superficial com o tema, em uma disciplina de curso de pós-graduação que iniciou, mas não concluiu. Ao ser perguntado sobre sua compreensão do que é CTS, o professor respondeu que:

Pelo que entendi da pouca leitura que fiz é que é uma nova maneira de refletir sobre a relação da ciência com a sociedade. Pensar de que forma a sociedade lida com a ciência. Sei que tem relação com os estudos de Paulo Freire, visando uma educação emancipatória. Como disse, meu contato foi pouco com o assunto (P3, Entrevista). 
Diante das falas dos professores, foi discutido o que é CTS, trazendo essas discussões para o ambiente escolar e social, como a perspectiva de desenvolver no estudante o senso crítico, trabalhando com temas e assuntos científicos e tecnológicos relevantes para a sociedade.

Para a efetivação desse pensamento em suas práticas pedagógicas, considera-se como entrave os resquícios de uma visão positivista da ciência, como apontam as falas abaixo:

Esse avanço a gente vê em várias áreas diferentes, na saúde com descobertas de remédios aparelhos que salvam vidas, na sociedade como um todo e, é claro na escola, mas a escola precisa fazer um elo entre esses fatos históricos e a realidade de hoje (P7, Entrevista).

Sendo assim, considerar as propostas educacionais CTS no processo ensinoaprendizagem é pensar mudanças conceituais sobre a inter-relação ciência-tecnologiasociedade, como também nos saberes necessários à prática docente. A convergência desses dois fatores possibilitará o refletir sobre o currículo escolar, buscando formas de superar fragmentações do conhecimento, bem como sobre metodologias arcaicas alicerçadas à abordagem tradicionalista de ensino.

A subcategoria "Interdisciplinaridade e Contextualização" congregou as reflexões dos professores sobre o tema, suas concepções prévias e compreensões sobre os conceitos. Suas falas indicam compreensões do que é um trabalho desenvolvido sob a égide da contextualização e da interdisciplinaridade:

Impossível discutir assuntos em sala de aula sem colocar sua opinião (P1, Encontro 5 e 6).

É falar da Química, da Física também falando do contexto social em que estes conhecimentos estão acontecendo (P2, Encontro 5 e 6 ).

Interagir com outras disciplinas (P3, Encontro 5 e 6 ).

Construir significados. (P4, Encontro 5 e 6).

Conseguir relacionar a sua disciplina com todas as outras (P 5, Encontro 5 e 6).

Tanto no que se refere à contextualização, quanto à interdisciplinaridade, as falas indicam que os professores trazem incongruência no discurso sobre ambos os conceitos, sem fundamentação teórica. Quando apresentam atividades desenvolvidas com os estudantes, que classificam de abordagens interdisciplinares e contextualizadas, promovem ações mais vinculadas ao cotidiano do que a contextualização. Realizam nas atividades aproximação do conteúdo com a realidade, mas não se amplia o conhecimento além dessa realidade, fator observado na fala de P3: 
$\mathrm{Eu}$, por exemplo, trabalhei com os alunos sobre ácidos, dividi a turma em grupos e inventamos de fazer receitas com alimentos ácidos, fizemos pavê, mousse, e um aluno que não faz nada na sala, não copia, não responde atividades, assumiu a responsabilidade da atividade, preparou o mousse de maracujá, fez o cartaz com exemplos de ácidos orgânicos que encontramos nos alimentos, os ácidos que fazem mal a saúde (P3, Encontro 3 e 4).

Sobre esta cotidianização, Wharta, Silva e Bejarano (2013, p. 2) apontam que "uma prática pedagógica baseada na utilização de fatos do dia a dia para ensinar conteúdos científicos pode caracterizar o cotidiano em um papel secundário, ou seja, estar servindo como mera exemplificação ou ilustração". Para os autores, nessa perspectiva, "adotar o estudo de fenômenos e fatos do cotidiano pode recair numa análise de situações vivenciadas por alunos que, por diversos fatores, não são problematizadas e consequentemente não são analisadas numa dimensão mais sistêmica como parte do mundo físico e social" (Wharta, Silva e Bejarano, 2013, p. 02).

\section{Dimensão Pedagógica}

A dimensão pedagógica compreende pensar o Ensino de Ciências considerando fatores democráticos, cívicos, culturais, sociais. Tem por objetivo suscitar a necessidade de considerar a prática pedagógica inter-relacionada com o conhecimento científico, estimular reflexões indispensáveis ao processo educativo, promover a compreensão de que esse processo é parte de uma construção emancipatória de aprendizagem, de uma educação escolar holística que considere no mesmo patamar questões éticas, sociais, culturais, políticas e conceituais. Pensar a dimensão pedagógica é desafiar o grupo de estudo a pensar suas práticas por outras vertentes, como destaca Angotti e Auth (2001, p. 23), envolver/comprometer os professores em atividades colaborativas, para inquietá-los e desafiá-los em suas concepções de ciência, de 'ser professor' e em suas limitações nos conteúdos e nas metodologias. [...] buscamos desencadear o processo de ensino-aprendizagem com vistas a superar a fragmentação excessiva ainda fortemente presente, principalmente no nível médio.

Apresentamos a seguir, as subcategorias que compreendem a categoria "Dimensão Pedagógica".

$\mathrm{Na}$ subcategoria “Abordagem CTS e processo ensino-aprendizagem”, buscou-se identificar quais as ideias e compreensões dos docentes em relação ao processo ensino- 
aprendizagem e as possíveis contribuições da Educação CTS para esse processo. As discussões realizadas foram de extrema importância, pois auxiliaram o grupo a refletir sobre processos formativos, concepções de ensino, metodologias e suas influências nos problemas encontrados em sala de aula, desde a indisciplina dos estudantes até a não participação nas propostas de ensino.

Os cursos oferecidos pela SEED tentam direcionar o professor, "dão a ideia do que trabalhar e como trabalhar" (P4, Entrevista), mas ao mesmo tempo não oferecem condições para que esse trabalho se desenvolva, fator sentido pela falta de material pedagógico, falta de tempo para estudo devido a atribulação do dia a dia do professor, contribuindo para que continue sua prática cotidiana sem muita reflexão sobre o processo de ensino.

A insatisfação dos professores com a formação continuada que recebem fica nítida em suas palavras. Criticam desde a organização dos eventos, as metodologias empregadas, os temas estudados, até a desvinculação com a prática pedagógica. É nítida a valorização que empregam a um processo formativo que favoreça a reflexão, tanto sobre conteúdos científicos e tecnológicos, quanto sobre questões sociais que estão presentes na sala de aula.

Nos primeiros encontros do grupo de estudo, quando instigados a relacionar situações que vivenciam e que inibem o desenvolvimento do ensino e, por conseguinte, inferem negativamente na aprendizagem dos estudantes foram apontados os fatores pessoais relacionados ao estudante, tais como a indisciplina e o desinteresse, e também fatores pessoais relacionado ao professor, relação professor e aluno, fatores estruturais como a falta de recursos em geral, fatores sociais incidindo sobre o papel da família e fatores pedagógicos relacionados a currículo e organização escolar:

É o desinteresse, e está associado a diversas coisas, às vezes é porque eles não sabem, o que a gente está falando está fora do seu contexto, do seu conhecimento, às vezes é porque basicamente não querem saber mesmo, às vezes são os problemas que trazem de casa que atrapalham o aprendizado deles e faz com fiquem desinteressados naquilo que a gente precisa ensinar naquela série, naquele momento (P1, Encontro 1 e 2).

A superlotação em sala é um dos principais problemas. Como trabalhar em uma sala com 40 alunos com os mínimos recursos que temos? (P5, Encontro 1 e 2).

Percebeu-se nas análises do grupo a falta de apontamentos relacionados a fatores conceituais e metodológicos de ensino, sendo esses fundamentais para o processo e diretamente 
relacionados à ação do professor em sala de aula. A abordagem CTS desenvolvida durante a formação com o grupo objetivou a reflexão sobre esses fatores. Sobre a atuação do professor em sala de aula.

Binatto (2015) sinaliza a necessidade de uma formação em CTS considerar o resgate da dimensão crítica do conhecimento (relevância dos aspectos conceituais), como de aprimorar o trabalho de favorecimento da compreensão tecnocientífica e de espaços críticos, fomentando cada vez mais o processo de alfabetização científica (relevância das questões políticas e sociais). O entendimento dos professores sobre formações eficientes, que supram suas necessidades enquanto educadores, congregam com as categorias de Binatto (2015), isso pode ser observado em suas falas:

Romper com a ideia de que a ciência está longe da vida das pessoas. A ciência está aí para ajudar - desde que o homem tenha discernimento para seu uso (P1, Encontro 3 e 4).

A proposta do CTS é discutir como ações influenciam a sociedade e a vida de cada um (P2, Encontro, 3 e 4).

Observou-se que o grupo evoluiu no sentido de manifestar reflexões sobre o ensino contextualizado e a interdisciplinaridade ao tratar de planejamento de atividades direcionadas aos estudantes, construindo a consciência de que o conhecimento não se apresenta numa constituição linear. O estudo do grupo coadunou com a formulação da Sequência Didática, buscando garantir a articulação da tríade CTS. O grupo elegeu o tema álcool para pensar a sequência didática, considerando-o como um problema social para os estudantes. Assim, a sequência didática proposta pelos professores envolveu os conceitos científicos: efeito do álcool no organismo, processo de produção de algumas bebidas alcoólicas, índices de acidentes provocados por uso abusivo de álcool. Foram tratados também os aspectos tecnológicos como construção e funcionamento do bafômetro, organização de dados levantados para discussão em relação ao consumo e efeitos do álcool no organismo, leitura de informações contidas nos rótulos de produtos que apresentam teor alcoólico, visita a laboratório de ciência.

A "Produção da Sequência Didática" envolve a segunda subcategoria da dimensão pedagógica. Para a organização da sequência didática, foram retomados alguns pontos importantes da Educação CTS como a inter-relação entre ciência, tecnologia e sociedade, a importância de se envolver nas atividades que serão propostas aos estudantes questões éticas, 
sociais, culturais, legais, econômicas e possibilitar que eles reflitam e tomem decisões a partir dessas reflexões.

Feito isso, foi dada ao grupo a liberdade de pensarem e elaborarem a sequência didática conforme suas compreensões. A sequência didática desenvolvida pelo grupo propôs atividades de construção de significados em relação aos conceitos científicos, visando contribuir para que os estudantes compreendam todas as nuances que envolvem o tema, bem como para refletirem e posicionarem-se criticamente frente a esses conceitos e fatores sociais que os envolvem. A dimensão pedagógica apresenta estratégias de ensino como pesquisa, debates, oficinas, trabalhos em grupos e experiências que auxiliam na interação em sala, concomitante a reflexões éticas, morais e sociais. É importante salientar a importância dos componentes curriculares que compõem a Ciência da Natureza no Ensino Médio: Química, Física e Biologia como bases para a construção de um conhecimento amplo, seja conceitual ou social, seja no desenvolvimento da capacidade crítica e reflexiva dos jovens, objetivando tomadas de decisão conscientes.

Ao pensar os objetivos da sequência diante do tema estabelecido, decidiu-se: por 1) iniciar o processo de formulação de opinião crítica sobre o consumo de bebidas alcoólicas; 2) analisar os aspectos gerais do álcool desde o seu conceito até os seus efeitos. Os objetivos apontam o passo inicial do desenvolvimento da sequência didática de abordagem CTS, trazendo duas concepções importantes: incentivar a formulação de opiniões sobre o assunto e estudar seus conceitos.

O grupo optou por organizar uma sequência didática interdisciplinar envolvendo os componentes curriculares: Química, Física, Biologia. Os conteúdos propostos vão além desses componentes curriculares, abordando temáticas de aspectos sociais, éticos, políticos, culturais, legais e de saúde pública. Considerando que a educação CTS oportuniza espaços de rompimento com a fragmentação disciplinar e possibilita construir interfaces com diferentes áreas do conhecimento e a apropriação de múltiplas relações conceituais, uma proposta interdisciplinar abre caminho para uma nova postura, delineia mudanças de atitudes, "uma postura interdisciplinar" (Fazenda, 1998).

Outro passo importante no desenvolvimento da sequência, foi o de conduzir os estudantes em pesquisas e desenvolver estratégias de ensino para a caracterização de uma problemática envolvendo o tema álcool, considerando questões econômicas e políticas (produção, consumo), questões sociais (leis e punições, consequências sociais, índices de 
acidentes, interações sociais), questões pessoais (efeitos no organismo: danos e benefícios), questões científico-tecnológicas (visitas a ambientes não formais de aprendizagem, realização de estudos sobre concentração de álcool no organismo, alteração de pressão, vapor, evaporação e realização de experiências científicas). Os componentes curriculares de Química, Física e Biologia são abordados na medida em que cada tema é desenvolvido pelos estudantes. Há de se considerar ainda propostas de leitura e debate em grupos que auxiliam na promoção e desenvolvimento da interpretação, desenvolvimento do pensamento crítico e argumentação.

Sobre o desenvolvimento do pensamento crítico do estudante P2 salienta a necessidade de o professor também ampliar seu pensamento. Segundo ele:

Como se pode pensar em desenvolver pensamento crítico do estudante quando o próprio professor mantém uma visão tradicionalista, não se abre para novos conhecimentos. Você pegar um tema que emerge das discussões dos estudantes, envolver fatores sociais exige que se busque novos métodos de ensino, que se estude para também ter o que argumentar ou direcionar as discussões dos estudantes (P2, Encontros, 8 e 9).

A proposta do grupo apresenta várias inter-relações CTS, à medida que propõe contextualizar conteúdos disciplinares por meio de temática social que faz parte do contexto dos estudantes. Os conteúdos propostos contribuem para o desenvolvimento do pensamento crítico ao propor pesquisas científicas, discussões dos temas pesquisados e debates que suscitam a argumentação, como também na abordagem de aspectos sociais e científicos, que direciona os estudantes a tomar posição diante do tema. Strieder (2008) destaca a necessidade de os estudos CTS possibilitarem a diversidade de posicionamento, como também de garantir duas características comuns e fundamentais: (i) um modelo de ensino que contribua para uma mudança da compreensão do papel da ciência e da tecnologia na sociedade, (ii) desenvolvimento de uma aprendizagem social, oportunizando a utilização de conhecimentos escolares que permitam o posicionar-se criticamente e tomar decisão sobre questões relacionadas a contexto científico-tecnológico.

Importa promover o envolvimento do estudante com o conhecimento científico. A esse respeito, P3 destaca:

No estudo da Química é bem produtivo envolver o dia a dia dos estudantes e não é difícil trabalhar de maneira interdisciplinar e contextualizada pois a Química envolve vários conhecimentos. E também dá para trabalhar com os poucos recursos que temos, as vezes até sem laboratório. Então coisas do cotidiano podem ser problematizadas 
para que eles entendam o conceito, discutam esse conceito de outras perspectivas (P3, Encontro, 8 e 9).

Binatto (2015) elencou quatro categorias consideradas de extrema importância em uma proposta de formação de professores e em especial professores da área da Ciência. Para Binatto (2015) em processo de formação os professores precisam ir além da compreensão conceitual dos pressupostos CTS e adquirir uma visão mais realista da natureza da C\&T permeando por conhecimentos social e político, que envolvem interesses e relações econômicas como forma de superar o mito salvacionista e o determinismo tecnológico. A sequência didática produzida pelo grupo, balizada pela Educação CTS foi analisada a partir das categorias de Binatto (2015):

QUADRO 2: ANÁLISE DA SEQUÊNCIA DIDÁTICA

\begin{tabular}{|c|c|}
\hline Categorias & Relação CTS e formação de professor \\
\hline $\begin{array}{l}\text { Relevância } \\
\text { das questões } \\
\text { políticas e } \\
\text { sociais }\end{array}$ & $\begin{array}{l}\text { Observa-se que a SD contempla esta categoria na medida que aborda o estudo da legislação } \\
\text { brasileira sobre o uso do álcool, tendo a atenção para discutir o que é legal e moral no seu uso } \\
\text { e propõem refletir sobre as propagandas de bebidas alcóolicas. Propõem discutir o papel do } \\
\text { uso da bebida alcóolica nas interações sociais entre os jovens. Ambas propostas suscitam no } \\
\text { estudante o refletir, analisar e emitir opinião colocando em xeque conhecimentos empíricos. } \\
\text { Esta categoria contempla o objetivo proposto por Binatto }(2015 \text {, p. 41) de "discutir os conceitos } \\
\text { relacionados às interações entre Ciência, Tecnologia e Sociedade associados à problematização } \\
\text { da concepção de neutralidade de C\&T." }\end{array}$ \\
\hline $\begin{array}{l}\text { Tendência } \\
\text { democrática e } \\
\text { emancipatória }\end{array}$ & $\begin{array}{l}\text { A categoria Tendência democrática e emancipatória é contemplada na SD, observada na } \\
\text { Problematização inicial com a proposta de discutir se álcool é ou não uma droga e se traz ou } \\
\text { não problemas de saúde para quem dele faz uso, como na proposta de opinar se é correto ou } \\
\text { não dirigir depois de ter consumido bebida alcoólica. A categoria é contemplada na } \\
\text { Organização do Conhecimento ao propor aos estudantes o estudo de conceitos científicos sobre } \\
\text { possíveis benefícios ou malefícios do uso do álcool, assim como conhecer e discutir a } \\
\text { legislação brasileira sobre esse consumo, sendo a proposta deste estudo vinculadas a estratégias } \\
\text { de ensino de debates e exposição dialogadas. Observa-se que a proposta de Binatto ( } 2015 \text {, p. } \\
\text { 41) para essa categoria de "problematizar temas sociais vinculados a C\&T, estimulando os } \\
\text { alunos a desenvolver um comprometimento social, indispensável na sociedade tecnológica em } \\
\text { que vivemos". }\end{array}$ \\
\hline $\begin{array}{l}\text { Relevância } \\
\text { dos aspectos } \\
\text { conceituais }\end{array}$ & $\begin{array}{l}\text { Sobre essa categoria Binatto }(2015, \text { p. 44) aponta que "no Enfoque CTS, a compreensão } \\
\text { conceitual, além do desenvolvimento de valores e atitudes, é imprescindível para a percepção } \\
\text { das implicações sociais de C\&T e também para a participação da sociedade nas definiçôes } \\
\text { relacionas a essas atividades". A categoria está presente na SD por propor o estudo da } \\
\text { legislação brasileira, os efeitos do álcool no organismo, identificar diferentes produtos que tem } \\
\text { o álcool como componente apontando pontos positivos do uso do álcool, construção de } \\
\text { bafômetro para medir teor alcoólico nos produtos, proposta de visita a laboratórios } \\
\text { universitários para discutir sobre doenças provocadas pelo uso do álcool, estudo de pressão e } \\
\text { vapor. }\end{array}$ \\
\hline
\end{tabular}




\begin{tabular}{|c|c|}
\hline Prática social & $\begin{array}{l}\text { Sobre a Prática Social Binatto }(2015, \text { p. } 45) \text { explana que "o contexto socioeconômico e a } \\
\text { realidade social podem ser o ponto de partida e de chegada de uma abordagem de ensino CTS". } \\
\text { Essa categoria é contemplada na SD, expressa na problematização inicial ao propor que os } \\
\text { estudantes pensem sobre prejuízos e benefícios do uso do álcool, reflitam sobre o consumo do } \\
\text { álcool entre os jovens e pensem sobre uso de álcool e direção. É contemplada na organização } \\
\text { do conhecimento ao propor estudo dos efeitos do álcool do organismo e a visita nos } \\
\text { laboratórios universitários a fim de discutir doenças provocadas por uso abusivo do álcool. } \\
\text { Está contemplada também, na aplicação do conhecimento, ao propor que os estudantes } \\
\text { retomem a problematização inicial e repensem sobre prejuízos e benefícios do álcool seja na } \\
\text { vida particular como social. }\end{array}$ \\
\hline
\end{tabular}

Fonte: Dados da Pesquisa

Em relação a organização da sequência destacam-se alguns pontos a serem melhorados, como a quantidade de tarefas para o número de horas-aula, um direcionamento mais preciso aos componentes curriculares indicando os conteúdos de cada componente curricular e pensar a ordem das atividades propostas, fatores que facilitam o desenvolvimento progressivo da aprendizagem dos estudantes.

A possibilidade de exporem a outros a pesquisa realizada promove interação entre os pares e entre os estudantes e professores, o que interfere positivamente nas relações sociais, aproximando os grupos. Essa possibilidade de interação foi salientada na fala do P2:

Essa abordagem de ensino é bem interessante, além de envolver mais o estudante com o conhecimento, mostrando que esse conhecimento tem relação com sua vida também ajuda na relação professor-aluno. A gente tem mais aproximação com eles, discute mais, conversa mais. É importante o estudante perceber que o conhecimento que ele tem importa, que é relevante e que o professor dá atenção a isso (Encontro, 8 e 9).

De maneira geral observa-se que a sequência didática abordou a tríade CTS, contemplando aspectos epistemológicos e pedagógicos de uma proposta de ensino, favorecendo um discurso interativo, a tomada de decisão, a criticidade e os aspectos éticos e sociais.

\section{Considerações Finais}

Esta pesquisa buscou inserir um grupo de professores da área da Ciências da Natureza de uma escola pública estadual nas discussões sobre a Educação CTS, considerando a possibilidade dessa concepção adentrar as suas salas de aula. Delineou-se pelo trajeto teórico da Educação CTS e seus pressupostos, abordando a formação continuada de professores das Ciências da Natureza, passando pela contextualização da Educação CTS, os entendimentos e desafios da formação continuada de professores, enfatizando a formação praticada no Estado do Paraná, bem como os axiomas dessa perspectiva. 
Buscou-se também durante a formação em serviço estudar o Pensamento LatinoAmericano em Ciência, Tecnologia e Sociedade, considerando a importância de refletir sobre problemas que estão mais próximos dos estudantes. Desenvolveu-se um exercício reflexão-ação sobre todo esse aporte teórico com vistas a verbalizar dimensões CTS que auxiliem a pensar uma nova maneira de ensinar, sendo este um fundamento importante para impulsionar mudanças na escola pública.

Com a realização da análise do corpus do trabalho constata-se que, mesmo pontualmente, existem indícios de uma prática pedagógica assentada em dimensões CTS. No entanto, essa prática muitas vezes prioriza o estudo de definições científicas, partindo de um currículo que considera em primeira mão o conteúdo programático, a construção linear do conhecimento e a reprodução de conceitos. Não se evidencia uma abordagem por temas sociais que possam ser contextualizadas.

Os professores demonstraram interesse pela forma de ensino interdisciplinar e contextualizada, desejando que façam parte de seus trabalhos em sala de aula e que possibilitem ações mais participativas dos estudantes. Aponta-se a necessidade de ter claros os conceitos de contexto e interdisciplinaridade para que o estudo não caia no espontaneísmo, prática em que fatores sociais são discutidos como mera ilustração, não servindo como reflexão sobre a real influência da ciência e da tecnologia na vida das pessoas.

As verbalizações do grupo quanto à compreensão dos pressupostos CTS, seus objetivos conceituais e sua aplicabilidade em processos formativos explicitaram entendimento da proposta, destacando posturas dialógicas que problematizam o desenvolvimento científicotecnológico. Também ficou marcada a necessidade de considerar outros saberes como parte de um processo de aprendizado e o desenvolvimento de atividades mediadas pelo debate e confronto de opiniões.

Mesmo o grupo tendo sinalizado a compreensão dos pressupostos CTS, a importância e o valor de sua aplicabilidade nos processos de ensino com vistas a superar muitos dos problemas apontados por eles nas entrevistas e no início do grupo de estudo, salienta-se que desenvolver essa prática na escola pública, constitui-se um desafio que requer mudanças conceituais, estruturais e atitudinais, exigindo maior clareza em relação à CTS. Não se descarta a necessidade da continuidade dos estudos e o aprofundamento dos conceitos CTS, quanto das abordagens metodológicas que auxiliam no seu desenvolvimento em sala de aula. 
Desenvolver uma educação que considere a tríade CTS impõe pensar além da simples organização curricular, ou de pautar-se em um trabalho que visa a transmissão de informações ou memorização. É, acima de tudo, auxiliar o estudante a pensar de maneira criativa e crítica e desenvolver uma nova postura diante do estudo e do seu papel social e político. Promover uma tomada de decisões mais consciente, em vistas da solução de problemas relacionados à sociedade em que vive uma vez que, propostas de ensino, embasadas pelos pressupostos CTS, contribuem significativamente para pensar o modelo social vigente, como a formação cidadã ofertada nas instituições de ensino visando a melhoria de condições de vida na sociedade. Entende-se que este é um grande desafio que a escola precisa enfrentar e assumir.

Uma continuidade para esse estudo deve considerar a tríade CTS, metodologias de aplicação desses pressupostos, como os três momentos pedagógicos, os tempos escolares e disponibilidade dos professores para dedicarem-se às leituras e discussões. Não há como estabelecer datas e horários precisos para um processo de formação em serviço, considerando a realidade da escola. Sendo assim, as horas-atividade dos professores nas escolas públicas são momentos relevantes para o processo, uma vez que esse período se destina tanto a organização do trabalho pedagógico, como a pensar e refletir sobre o processo ensino-aprendizagem.

Limitações à parte, é factível afirmar que a pesquisa em muito contribuiu para a disseminação dos pressupostos CTS, impactando positivamente o trabalho de pedagoga da pesquisadora e possibilitando que o grupo de professores refletissem sobre a organização de seu trabalho em sala de aula.

Geraldo (2020) aponta que muitas arguições apresentam os pressupostos da Educação CTS aos professores, mas não oferecem meios para um planejamento. A Educação CTS está posta, cabe agora inserir o professor na abordagem para que ele possa discutir e planejar ações por essa perspectiva de discutir temas problematizadores que estão dentro das salas de aula, pensar a realidade escolar vivenciando as inter-relações entre ciência, tecnologia e sociedade.

Sendo o Ensino Médio a última etapa da Educação Básica, é de suma importância uma educação pública que desperte os estudantes para a cidadania, para a reflexão sobre sua importância enquanto sujeitos e, assim, mesmo que a partir desta etapa não possam dar continuidade aos estudos, ou optem por cursos profissionalizantes, terão uma visão mais crítica diante da sociedade em que estão inseridos, terão condições de tomar melhores decisões diante das contrariedades e tensões sociais que possam sofrer. 


\section{Referências}

Acevedo Diaz, J. A.(1996). Cambiando la práctica docente en la enseñanza de las ciencias a través de CTS. Biblioteca Digital da OEI (Organização de Estados Iberoamericanos para a Educação, a Ciência e a Cultura.

Alferes, M. A.; Maninardes, J. (2011). A Formação Continuada de professor no Brasil. In: SEMINÁRIO DE PESQUISA DO PPE, 2011. Anais [...] Maringá: PPE.

Alvarado-Prada, L. E., Freitas, T. C. e Freitas, C. A. (2010). Formação continuada de professores: alguns conceitos, interesses, necessidades e propostas. Revista Diálogo Educacional, 10(30), 367-387.

Angotti, J. A. P. Auth, M. A. (2001). Ciências e Tecnologia: Implicações sociais e o papel da

Educação. Revista Ciência \& Educação, 7(1), 15-27.

Auler, D.; Delizoicov, D. (2001). Alfabetização Científico-tecnológica para quê? Demétrio Delizoicov. Revista Ensaio, 3 (2), 122-134.

Bardin. L. (1977). Análise de conteúdo. Lisboa (Portugal): Editora Edições 70.

Binatto, P. F. (2015). Enfoque ciência, tecnologia e sociedade (CTS) na formação reflexiva de futuros professores de biologia: possibilidade, desafios e contribuições. 2015. Dissertação (Mestrado em Ciências e Matemática) - Universidade Estadual do Sudoeste da Bahia, Jequié (Bahia).

Brasil (1996). Lei de Diretrizes e Bases da Educação 9.394/96. República Federativa do Brasil, Brasília, 1996.

Centa, F. G. (2015). “Arroio Cadena: Cartão Postal de Santa Maria?”: Possibilidades e Desafios em uma Reorientação Curricular na Perspectiva da Abordagem Temática. 2015. Dissertação (Mestrado em Educação Matemática e Ensino de Física) Universidade Federal de Santa Maria, Santa Maria (Brasil).

Chrispino, A. (2017). Introdução aos enfoques CTS na educação e no ensino. Rio de Janeiro (Brasil): IBERCIENCIA.

Delizoicov, D. (2002). Problemas e Problematizações. In: Pietrocola, M. (org.). Ensino de Física? Conteúdo, metodologia e epistemologia numa concepção integradora. Florianópolis (Brasil): UFSC.

Delizoicov, D., Angotti, J. A. e Pernambuco M. (2001). Ensino de ciências: fundamentos e métodos. São Paulo (Brasil): Cortez.

Fazenda, I. (1998). Interdisciplinaridade: história, teoria e pesquisa. 4. ed. Campinas (Brasil): Papirus.

Freire. P. (1996). Pedagogia da autonomia: saberes necessários à prática educativa. 37. ed. São Paulo (Brasil): Paz e Terra.

Geraldo, A. (2020). Aspectos didáticos e pedagógicos da Educação CTS no Ensino Médio: uma análise do componente curricular Ciências Aplicadas da rede SESI-PR. Dissertação (Mestrado em Ciências e Matemática) - Universidade Federal do Paraná, Curitiba (Brasil). 
Kato, S. Kawasaki, S. C. (2011). As concepções de contextualização do ensino em documentos curriculares oficiais e de professores de ciências. Ciências \&Educação, 17(1), 35-50.

Mazza, V. A., Melo, N. S. F. e Chiesa; A. M. (2009). O Grupo focal como técnica de coleta de dados na pesquisa qualitativa: relato de experiência. Biblioteca Digital de periódicos, 14(1), 183-188.

Maués, O. (2003). A Política na formação de professores: "a universalização” e a prática. Séries Estudos, 5(3), 165-179.

Pimenta, S. G. (1999). Formação de professores: identidade e saberes da docência. In: Pimenta, S. G. (Org). Saberes pedagógicos e atividade docente. São Paulo (Brasil): Cortez Editora.

Santos, W. L. P.; Mortimer, E. F. (2000). Uma análise de pressupostos teóricos da abordagem C-T-S (Ciência - Tecnologia- Sociedade) no contexto da educação brasileira. Revista Ensaio, 1(2), 110-132.

Silva, M. A. A. da (2016). Ciência, tecnologia e sociedade, experimentação e formação inicial de professores de química: explorando possibilidades. 2016. Dissertação (Mestrado em Educação Científica e Formação de Professores) - Universidade Estadual do Sudoeste da Bahia, Jequié (Brasil).

Siemsen, G. H. (2019). O Ensino de Astronomia em uma abordagem interdisciplinar no Ensino Médio: potencialidades para a promoção da alfabetização científica e tecnológica. 2019. Dissertação (Mestrado em Educação em Ciências e Matemática) - Universidade Federal do Paraná, Curitiba (Brasil).

Strieder, R. B. (2008). Abordagem CTS e Ensino Médio: espaços de articulação. 2008. Dissertação (Mestrado em Ensino de Ciências) - Universidade de São Paulo, São Paulo (Brasil).

Strieder, R. B. (2012). Abordagens CTS na educação científica no Brasil: sentidos e perspectivas. 2012. Tese (Doutorado em Ensino de Ciências) - Universidade de São Paulo, São Paulo (Brasil).

Whartha, E. J., Silva, E. L. e Bejarano, N. R. R. (2013). Cotidiano e Contextualização no Ensino de Química. Química Nova Escola, 35(2), 84-91.

Zabala, A. (1998). Prática Educativa: como ensinar. Porto Alegre (Brasil): ARTMED, 1998.

Autores

Rosangela Cristina Rocha Auriglietti

Possui graduação em Pedagogia pela Faculdade de Filosofia Ciências e Letras de Cornélio Procópio (2001). Pós-Graduada em Psicopedagogia e Educação Especial pelo CIPPEX e em Mídias Na Educação pela UFPR. Atualmente é concursada como Pedagoga e Professora na Secretaria de Educação do Estado do Paraná. Cursou o Programa de Desenvolvimento Educacional - PDE, oferecido pelo governo do Estado do Paraná, (2014/2015).rcrrosangelarocha@,gmail.com https://orcid.org/0000-0002-5317-0041 Universidade Federal do Paraná- UFPR Curitiba - PR 
Leonir Lorenzetti

Possui graduação em Ciências Habilitação Em Biologia pela Universidade do Contestado (1989), mestrado em Educação pela Universidade Federal de Santa Catarina (2000) e doutorado em Educação Cientifica e Tecnológica pela Universidade Federal de Santa Catarina (2008). Atualmente é professor da Universidade Federal do Paraná, atuando no Departamento de Química e no Programa de Pós-Graduação em Educação em Ciências e Matemática, atuando na Linha Educação em Ciências. Atua também no Programa de Pós-Graduação em

Formação Científica, Educacional e Tecnológica da Universidade Tecnológica Federal do Paraná. Lider do Grupo de Pesquisa Alfabetização Científica e Tecnológica na Educação em Ciência. Atuou no Pibid como Coordenador de Área de Gestão de Processos Educacionais no período de 2014 a 2018. Atuou no Programa Licenciar da UFPR. Atuou como Coordenador do Pibid de Área do Curso de Ciências Biológicas (2018 a 2020). Coordenador do Curso de Química (Janeiro a março de 2020). Coordenador da Coordenadoria de Atividades Formativas e Estágios (Abril 2020 - atual) Tem experiência na área de Educação, com ênfase em Ensino de Ciências, Ensino de Biologia e Ensino de Química, atuando principalmente nos seguintes temas:Alfabetização Científica e Tecnológica, CTS, Educação Ambiental, Formação de Professores, Epistemologia de Fleck, Pesquisa do Estado da Arte. leonirlorenzetti22@gmail.com http://orcid.org/0000-0002-0208-2965 Universidade Federal do Paraná - UFPR Curitiba - PR. 